\title{
The Perception of Learners with Mobility Constraints on Environmental Accessibility Elements In Oyo State, Nigeria
}

\author{
Oluokun, Philip Olusunmade
}

Federal College of Education (Special), Oyo, Oyo State School Of Special Education

Department of Education for Learners with Physical and Health Impairment

oluokunsunmade@rocketmail.com

08060190745

\begin{abstract}
The main focus of this paper is to investigate the perception of learners with mobility constraints on environmental accessibility elements, simple random technique was used to select one hundred and twenty two students with mobility constraints in three (3) tertiary institution in Oyo State. It was deduced from the findings that most buildings in the schools are not accessible to learners with mobility constraints. Blindness imposes a great limitation to the overall wellbeing of an individual for the singular reason of inability to move around independently. People with severe visual limitation are often dependent on others or on artificial aid for independent travels. They often get frustrated and sometimes get stranded. Apart from barriers that are structural within the environment, (i.e. buildings and other constructions) there are many other designs which constitute hindrances and make the environment both inaccessible and unfriendly to person with physical impairment. Example of such includes simple home appliances, machines and tools as well as many other utilities; such as automobiles, computers, lifts, travelators etc. It was recommended from the findings that accessible elements should be incorporated into the school environment. Learners with mobility impairments, require sufficient space to approach and open doors. Additionally, since doors with significant resistance will be difficult to open for learners with mobility impairments, they should not be used at entrances. Clearance space is required beyond the latch side of doors to provide for optimum maneuverability. Latch-side space of at least 18 inches is required for forward approaches, and the clearance space in front of the door must be at least 60 inches deep for the pull side of doors.
\end{abstract}

\section{INTRODUCTION}

According to the World Bank and World Health Organization report, Persons with Disabilities (PWDs) are about 15 per cent of the world's population and most of these persons live in the rural areas of developing countries. Many of these persons lack equal access to health care, education, job opportunities and other necessary services. One of the challenges that prevent their access to possible independence and their use of public spaces is the lack of attention to their physical and mobility needs, which results to isolation and deprivation of their human rights. The issue of access to public buildings has received little attention in some countries in Africa, leading to the deprivation of a large number of people from enjoying their legal rights on an equal footing with other members of the society. Consequently, disability has caused many problems at family and societal levels, since people with mobility constraints have been deprived of accessing their fundamental right such as the rights to health and education among a host of others, they are often unable to utilize their talents and their families cannot properly look after them as there are limited facilities available for their care. 
Accessibility implies making public places accessible to every individual, irrespective of his or her disability or special need, ensuring the integration of the wheelchair user into the society and thereby granting them the capability of participating in activities of daily living and ensuring equality in daily life.

Easy access to public facilities especially, buildings and roads, is beneficial for participation in civic life and essential for education, health care, and labor market participation. Lack of access can exclude people with disabilities, or make them dependent on others. When public facilities are inaccessible, people with mobility constraints who have physical disabilities and those with visually impaired, will find it difficult to participate in everyday life. Transportation provides independent access to employment, education, and health care facilities, and to social and recreational activities. Without accessible transportation, people with visual impairment are more likely to be excluded from services and social contact. In a study in Europe, transport was a frequently cited obstacle to the participation of people with disabilities. In a survey in the United States of America lack of transportation was the second most frequent reason for a person with disability being discouraged from seeking employment. The lack of public transportation is a major barrier to access, even in some highly developed countries.

Putnam (2013), noted that although access of People with mobility constraint to higher education is slowly gaining momentum from time to time and from place to place, equality with regard to access has remained unattainable in most countries of the world including Nigeria. The traditional barriers for inaccessibility of higher education for those with disabilities might arise from variety of circumstances, particularly from two likely premises: one is that their needs are assumed to be expensive to cover, and the second is that people with mobility constraint are under rated that cannot perform required qualification criteria for higher education (Willeh., 2002).

Regarding undermining attitude in the Nigeria context, Tirussew (2004) indicated "in Nigeria, People with mobility constraint are perceived as "weak, hopeless, dependent, unable to learn and subject of charity". By assessing and revealing the conditions, challenges as well as by suggesting recommendations, the situation of learners with mobility constraints could be improved. When it comes to the education of people with mobility constraint, especially in the tertiary institutions, barriers and difficulties to environmental accessibility are numerous.

As Evans (1998) noted, accessibility is shift services from simply trying to fit the child into "normal settings"; it is a supplemental support for their disabilities or special needs and promotes the child's overall development in an optimal setting. Putnam, Geenen, (2003) defined accessibility as Inclusive, programme that respect differences and celebrates diversity. The focus is creating environments responsive to the differing developmental capacities, needs, and potentials of all students. It is also viewed as adjustments and accommodations that incorporate creative solutions. Accessibility from legal and standard perspectives refers to what the law requires to enable the reaching or approaching of something. Accessibility is the presence of facilities that enable the easy entry and use of a public building by persons with mobility constraints.

Despite the demands faced by institutions, there were definite signs of progress in provision for students with disability problems. Most institutions had at least one designated disability officer and a senior manager with responsibility for disability issues. Studies conducted in the area revealed gaps between policy and practice and showed that significant barriers remain in participation of students with disability in higher educational institutions. Most importantly there have been identified areas needing particular attention such as physical environment accessibility, teaching and learning, monitoring and evaluation and staff development. Depending on their particular impairment, most of the students experience barriers to accessing their education relating to the physical environment or teaching and learning at some point during their studies. In addition, the institution and course choice of some students have been affected by physical access issues. Besides classrooms, ICT 
laboratory and dormitories, the access to dining halls, toilet rooms, wash rooms and playgrounds have been the great concern of people with mobility constraints specifically on those with physical and visual impairments. Michigan State Board of Education Revised Rules (1988). In general, the study aim to assess the perception of learners with mobility constraints on environmental accessibility in Oyo State.

\section{Statement of the Problem}

The perception of person with mobility constraint is that they cannot perform like the normal person some certain tasks although many assistive technology devices that can help them in their daily living skills. This perception of person with mobility constraints continues to hinder both their academic pursuit and their daily life. This study is aimed at investigating the perception of person with mobility constraint on environmental accessibility.

\section{PuRpose OF THE STUdy}

The main purpose of the study is to investigate the perception of person with mobility constraint on environmental accessibility. Specifically, the main purpose of this study is to;

- know the perception of person with mobility constraint on environmental accessibility in Oyo State

- know if the buildings on campuses are accessible to learners with persons with mobility constraints

- know the measure that are put in place to aid learners with mobility constraint

\section{RESEARCH QUESTIONS}

The following research questions are raised to guide the study:

- What are the perception of learners with mobility constraint on environmental accessibility?

- Are buildings on campuses accessible to learners with mobility constraints?

- What measures are being put in place to aid learners with persons with mobility constraints?

\section{SigNIFICANCE OF THE STUDY}

The study will be significant to learners with mobility constraint specifically, people with visual impairment and physical disabilities on how to make the environment accessible for them. It also will help the stakeholders of education for person with mobility constraint to know the measures to put in place on environmental accessibility in order to help persons with mobility constraints.

\section{LITERATURE REVIEW}

\section{Mobility Constraints of Persons with Physical and Health Impairment}

Most mobility limitations result from a broad range of neuromuscular and orthopedic disabilities that produce wide variations in the nature and extent of the remaining physical functions. It is not appropriate to generalize with regard to specific limitations of persons with these kinds of disabilities. Functional abilities vary widely not only among the disabilities, but also among students with the same disability. General conditions affecting the degree of limitation may include age at onset, progression rate, disorder, level and extent of injury, and response to treatment. Some disabilities are progressive (as in muscular dystrophy); others are not. Limitations associated with some disabilities fluctuate with periods of remission and exacerbation (as in multiple sclerosis and arthritis), some may remain constant (as in spina bifida), and others may improve with time and therapy.

When assessing public environments, particular attention should be paid to the conflicting needs of different groups of individuals to ensure access for the greatest number. For example individual with visual impairments interpret the environment more easily if tactile information is provided on the ground (e.g. distinct lip between 
the road and the sidewalk). On the other hand, wheel chair users prefer uniform surfaces that are easier to travel on (Gamache, Morlaes, Noreau, Dumont, and Leblond (2018).

The student with the disability is the best source of information regarding the disability and accompanying specific limitations. Student Disability Services can also provide information about various disabilities.

Although it is difficult to generalize about classroom needs of students with physical disabilities, the major limitations affecting college participation generally involve mobility and hand dexterity.

Environmental accessibility can be described in terms of mobility within the environment. Mobility is defined as the movement of moving from one place to another barring any form of barrier gracefully and safely within the environment. Environment differs from place to place in terms of topography as well as in planning. An environment is said to be accessible when it allows easy movement of persons and goods. When environments are planned, it is basically so that people can have access to all the facilities and infrastructures available within such environments. By safety, it is assumed that a person can encounter certain difficulties while moving within an environment.

Free movement in public places is assumed by most people to be a right. Accesses to public transportation, easy movement along streets and through buildings as well as clear routes in emergency situations are all elements of an accessible environment Shannon Crum and Kenneth Foote (2006). But while it is desirable to have accessible environment, the environment is not totally accessible to everyone and in the view of some experts, neither should it be. For instance, there are very good reasons for limited access in situation which may be dangerous to children, construction sites which endanger the safety and security of people, as well as other highly restricted places in the environment.

According to Shannon Crum and Kenneth Foote (1996), barriers are those aspects of the built environment, which lessen a person's access (especially the disabled). The most immediate type of barrier for a wheelchair user is clearly any object which impedes or restricts the movement of the wheelchair;

Some of these may include;

i. $\quad$ Parts of buildings

ii. Landscaping

iii. Walkway

iv. Parking area

v. High curbs

vi. Gravel walkways

vii. Narrow sidewalks

viii. Heavy doors requiring force to open

ix. Narrow doorways

x. Swinging doors

Apart from barriers that are structural within the environment, (i.e. buildings and other constructions) there are many other designs which constitute hindrances and make the environment both inaccessible and unfriendly to person with physical impairment. Example of such include simple home appliances, machines and tools as well as many other utilities such as automobiles, computers, lifts, travelators etc. Shannon Crum et al observed that until the 1970's people with physical impairments were not generally expected to participate in day to day 
life. Many of them were catered for by family members or in some cases, institutionalized. Only a few of them were expected to hold jobs outside the home because their conditions were not so serve. Connor, (2015).

Improved medical care, particularly emergency medicine, brought about change in their situation. After the war in Vietnam, a sizeable number of veterans returned to the United State with physical disabilities as a result of injuries, were not satisfied to remain at home. They wanted to hold jobs and participate in everyday life and therefore, they began to lobby for change. This is the background to the struggle that later paved way for several legal considerations in favor of the handicapped in the U.S.A.

\section{Mobility Constraints of Persons with Visual Impairment}

Blindness imposes a great limitation to the overall wellbeing of an individual for the singular reason of inability to move around independently. People with severe visual limitation are often dependent on others or on artificial aid for independent travels. They often get frustrated and sometimes get stranded. Kathleen, R. (2013).

Physical Barriers

Eliminating physical barriers to access benefits everyone. These are examples of how to address issues and barriers that individuals with mobility and sensory impairments face.

Wheelchair Maneuvering

- Hallways, passageways and other routes must allow for wheelchair access.

- Hallways and passageways must be an appropriate width to allow for passage. For newer construction, this is generally a minimum of 36 inches.

- Where routes turn around an obstruction, additional clar space may be required to allow navigation around the obstruction.

- Sufficient passing space - at least 60 inches at a minimum of 200 foot intervals for newer construction must allow for maneuvering past another person.

- Toilet rooms and other areas must allow for sufficient space for a wheelchair user to turn around.

- Surfaces must be firm, stable and slip-resistant. Carpeting that is thick, soft or loose can make wheelchair maneuvering difficult. Carpeting must be firmly secured, and of appropriate pile height and texture.

- Changes in level must be appropriately ramped.

- Opening in grates can be a hazard for someone using a wheelchair or a cane. These openings cannot exceed half an inch, and must be perpendicular to the direction of travel.

- Drinking fountains, sinks, dining tables and work areas should provide sufficient space for knee and leg clearance underneath.

\section{Maneuvering at Doors}

Individuals with mobility impairments, including those using wheelchairs, require sufficient space to approach and open doors. Additionally, doors with significant resistance will be difficult to open for individuals with mobility impairments.

- Clearance space is required beyond the latch side of doors to provide for optimum maneuverability. Latch-side space of at least 18 inches is required for forward approaches, and the clearance space in front of the door must be at least 60 inches deep for the pull side of doors.

- For the push side of doors, clearance space of at least 48 inches is required in front of the door, with at least 12 inches of latch-side space. 
- Fixed objects, such as shelves, cannot protrude into the clearance space in front of doors.

- Thresholds can pose challenges for maneuverability. Thresholds cannot exceed a half inch. Thresholds greater than a quarter inch must be beveled at the edges.

- Heavy doors, or doors with strong closers, will be difficult for individuals with mobility impairments to open. The force to open interior doors cannot exceed five pounds.

\section{Toilet Rooms}

Toilet areas must allow for sufficient space to enter, navigate doorways, and maneuver within the room. Fixtures must be placed with accessibility in mind.

- Toilets must be located with sufficient clear space to allow for an approach by wheelchair.

- Grab bars near toilets are critical to allow transfer.

- Flush controls must be located on the open side of the toilet to be reachable.

- Clearances are required at sinks, soap dispensers, towel dispensers and hand dryers. These should be located at a height accessible to a wheelchair user.

- There should be sufficient clearance space in a single-user restroom to allow an occupant to turn around.

- In multi-user restrooms, at least one lavatory should be accessible.

- A stall with dual grab bars will assist individuals with ambulatory disabilities.

Protruding Objects

Objects that protrude into passageways can impede individuals with motor impairments, and can be hazardous to individuals with visual impairments. Examples include shelves, drinking fountains, and sculptures. People who are blind or low vision sometimes travel along walls for orientation.

- The placement of objects must still allow for sufficient navigation around the object by a wheelchair user.

- Protruding objects that are sufficiently high - above 80 inches - do not present a hazard. Similarly, protruding objects that can be detected by a cane are allowable. These objects are detectable at heights less than 27 inches.

- Protruding objects located between 27 and 80 inches can pose a hazard. These should not protrude more than four inches from a wall unless they are appropriately treated.

- Objects such as fire extinguishers and shelves may be recessed in a way to avoid a protrusion of greater than four inches.

- In the case of a fixed sculpture with protrusions, a platform or railing can alert people to maintain sufficient distance to avoid contact.

Parking and Passenger Loading Zones

Accessible parking areas must be dispersed to enable people to park near as many accessible entrances as possible.

- In parking lots, accessible parking spaces must have sufficient space and access aisles. Two spaces may share an access aisle.

- Access aisles are necessary to allow sufficient room to maneuver to and from the vehicle. 
The Perception of Learners with Mobility Constraints on Environmental Accessibility Elements In Oyo State, Nigeria

- The number of required accessible spaces depends upon the size of the parking facility.

- Accessible parking spaces must be designated by appropriate signage.

Classrooms

Classrooms should be inclusive spaces that allow for access and participation.

Arrangements may need to be made for a table, alternative chair or other equipment.

Seating must allow for a clear line of sight to the instructor and allow for equivalent participation.

Labs and fieldwork sites must also allow for usability and access.

\section{METHODOLOGY}

This study was a descriptive exploratory study that utilized a quantitative approach via survey research methods. It involved administering a survey to available and a randomly selected sample of students with physical disabilities and visual impairments in some selected public universities. In doing this the researcher tried to explore the sampled universities physical environment accessibility for persons with mobility constraints.

Data source of the study were students with physical disabilities and visual impairments sampled from five public universities. Throughout the study both primary and secondary data sources have been employed. Students who participated on reporting the survey were the primary sources of the study, and secondary sources such as different publications, books, magazine and documented materials have been used throughout the study.

Population of the Study

The study covers all the students with mobility constraints (both visual impairment and physical and health impairment) in University of Ibadan, Ibadan, Nigeria and Federal College of Education (Special), Oyo.

\section{SAMPLE}

A purposive sampling techniques was used to select one-hundred and twenty two mobility constraints students in the institution.

\section{RESEARCH INST041000RUMENTATION}

The study employed questionnaire as exclusive data collection tools. Following extensive review of related literatures, questionnaires dominantly with close ended items which has three parts modified and developed. The first part of the questionnaire was intended to gather demographic characteristics of respondents, the second part described about the educational backgrounds of respondents and the perception they posse regarding their respective universities of physical environment accessibility. And the final part of the questionnaire was likert type scales that has been measured on a scale range from 1 to 4 (1 strongly disagree, 2 disagree, 3 agree and 4 strongly agree). Before actual use the questionnaire has been piloted.

\section{DATA ANALYSis}

Table 1 What are the perception of person with mobility constraint on environmental accessibility?

\begin{tabular}{|l|l|l|l|}
\hline Variables & Perception & No & $\%$ \\
\hline & Inaccessible & 61 & 50.0 \\
\hline Buildings accessibility & Undecided & 27 & 22.1 \\
\hline & Accessible & 34 & 27.9 \\
\hline & Total & 122 & 100.0 \\
\hline
\end{tabular}

American Research Journal of Humanities and Social Sciences 
The Perception of Learners with Mobility Constraints on Environmental Accessibility Elements In Oyo State, Nigeria

\begin{tabular}{|l|l|l|l|}
\hline & Inaccessible & 76 & 62.3 \\
\hline Overall physical environment accessibility & Undecided & 23 & 18.9 \\
\hline & Accessible & 23 & 18.9 \\
\hline & Total & 122 & 100.0 \\
\hline
\end{tabular}

In addition to frequency-percentage analysis (Table 1), mean analysis was conducted for the respondents report on the two general statements which might better described the universities and college physical environment accessibility for persons with mobility constraint, i.e. campus buildings accessibility for persons with mobility constraint, and overall campus physical environment accessibility for persons with mobility constraint,. When the findings of the data explored.

Table 2 Means for buildings and overall physical environment accessibility _for persons with mobility constraints_

\begin{tabular}{|l|c|c|c|}
\hline Variables & No & Mean & SD \\
\hline Buildings accessibility & 122 & 1.78 & .858 \\
\hline Overall physical environment accessibility & 122 & 1.57 & .792 \\
\hline
\end{tabular}

Table 2 shows that the mean of the response for the statement accessibility of campus buildings for PWDs $n=$ 122 is 1.78, while it is 1.57 for the statement overall campus physical environment accessibility for persons with mobility constraint $n=122$, ( 1 inaccessible, 2 undecided and 3 accessible). In the study likert-type scale has been used to examine the respondents' perception of universities physical environment accessibility for persons with mobility constraint in more specific and detail manner. The responses on the likert-type scale has been measured on a scale range from 1 to 4 ( 1 strongly disagree, 2 disagree, 3 agree and 4 strongly agree). Statements presented in the likert scale intended to gather specific information from respondents regarding physical environment accessibility of universities for persons with mobility constraint. In general, the statements of the likert scale focused to obtain further information on the accessibility of universities physical environment for persons with mobility constraint such as learning rooms, libraries, laboratories, dormitories, corridors, circulation areas and bathrooms. In addition, statement on the accessibility of playgrounds and recreation cites of the universities for persons with mobility constraint were among the areas included to be investigated on the likert scale. Finally, statements that described the accessibility of the universities service provision buildings such as Banks and shopping centers were also included on the likert scale.

Table 3: Campus accessibility for persons with mobility constraints

\begin{tabular}{|l|l|l|l|l|}
\hline 1.Accessible transportations are available on campus for my & 2.01 & .864 & 1.62 & .493 \\
\hline needs & & & & \\
\hline 2. Sidewalks of the campus are barrier-free & 2.14 & 1.008 & 2.38 & 1.155 \\
\hline 3. Campus signs are easy to read and understand & 2.18 & .929 & 2.29 & 1.060 \\
\hline 4. There are curb cuts on the streets in key areas to allow users & 2.18 & .929 & 2.44 & 1.307 \\
\hline
\end{tabular}

The table above shows the accessibility of campus building entrances, bathrooms, corridors and circulation areas for the needs of the two impairment groups were also presented. In this regard, the perception of the two impairment groups showed variation.

\section{ConCLUSION}

It is conclude from the findings that most buildings in the school is not accessible for persons with mobility constraints. Blindness imposes a great limitation to the overall wellbeing of an individual for the singular reason of inability to move around independently. People with severe visual limitation are often dependent on 
others or on artificial aid for independent travels. They often get frustrated and sometimes get stranded. Apart from barriers that are structural within the environment, (i.e. buildings and other constructions) there are many other designs which constitute hindrances and make the environment both inaccessible and unfriendly to person with physical impairment. Example of such includes simple home appliances, machines and tools as well as many other utilities; such as automobiles, computers, lifts, travelators etc. Shannon Crum et al observed that until 1970's people with physical impairments were not generally expected to participate in day to day life. Many of them were catered for by family members or in some cases, institutionalized. Only a few of them were expected to hold jobs outside the home because their conditions were not so serve.

\section{Recommendations}

It is recommended from the findings that:

Maneuvering at Doors: Individuals with mobility impairments, including those using wheelchairs, require sufficient space to approach and open doors. Additionally, doors with significant resistance will be difficult to open for individuals with mobility impairments.

Clearance space is required beyond the latch side of doors to provide for optimum maneuverability. Latch-side space of at least 18 inches is required for forward approaches, and the clearance space in front of the door must be at least 60 inches deep for the pull side of doors.

Fixed objects, such as shelves, cannot protrude into the clearance space in front of doors.

Toilet areas must allow for sufficient space to enter, navigate doorways, and maneuver within the room. Fixtures must be placed with accessibility in mind.

\section{REFERENCES}

Kathleen, R. (2013). A child with another health impairment, Colorado, Department of Education; Slide 4.

Kendall, (1991). Exceptional children, Englewood Cliffs, NJ: Prentice-Hall.

Shannon Crum and Kenneth Foote (1996). Taking significant step in the right direction. https://doi. org/10.1177/001440298905600104. Vol. 1 pp. 94-94

Connor, F. P. (2015). The education of children with crippling and chronic medical conditions. In W. M. Cmickshank \& G. O. Johnson (Eds.), Education of exceptional children and youth (3rd ed.). 27-37.

Tenth Annual

Michigan State Board of Education Revised Rules (1988). Psychological considerations with crippled children. In W.M. Cruickshank (Ed.), Psychology of exceptional children and youth (3rd ed.), N.J.: Prentice-Hall, 40-45.

Gamache, S., Vincent, C., Routhier, F., McFadyen, B. J., Beauregard, L., \& Fiset, D. (2018) Development of a measure of accessibility to urban infrastructures: a content Validity study. Medical Research Archives, 4(5), 1-25

Citation: Oluokun, Philip Olusunmade, "The Perception of Learners with Mobility Constraints on Environmental Accessibility Elements in Oyo State, Nigeria".

American Research Journal of Humanities and Social Sciences. 2020; 6(1): 1-9.

Copyright (C) 2020 Oluokun, Philip Olusunmade, This is an open access article distributed under the Creative Commons Attribution License, which permits unrestricted use, distribution, and reproduction in any medium, provided the original work is properly cited. 